\title{
Vegetable Oil-Based Thiol-Ene/Thiol-Epoxy Resins for Laser Direct Writing 3D Micro-/Nano-Lithography
}

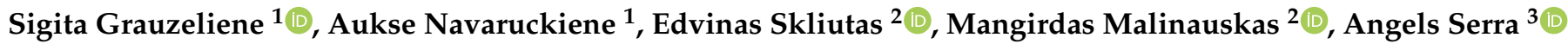 \\ and Jolita Ostrauskaite ${ }^{1, *}$ \\ 1 Department of Polymer Chemistry and Technology, Kaunas University of Technology, Radvilenu Rd. 19, \\ LT-50254 Kaunas, Lithuania; sigita.grauzeliene@ktu.lt (S.G.); aukse.navaruckiene@ktu.lt (A.N.) \\ 2 Laser Research Center, Faculty of Physics, Vilnius University, Sauletekis Ave. 10, LT-10223 Vilnius, Lithuania; \\ edvinas.skliutas@ff.vu.lt (E.S.); mangirdas.malinauskas@ff.vu.lt (M.M.) \\ 3 Department of Analytical and Organic Chemistry, Universitat Rovira i Virgili, C/Marcel-lí Domingo s/n, \\ Edifici N4, 43007 Tarragona, Spain; angels.serra@urv.cat \\ * Correspondence: jolita.ostrauskaite@ktu.lt; Tel.: +370-37-300-192
}

check for updates

Citation: Grauzeliene, S.;

Navaruckiene, A.; Skliutas, E.;

Malinauskas, M.; Serra, A.;

Ostrauskaite, J. Vegetable Oil-Based

Thiol-Ene/Thiol-Epoxy Resins for

Laser Direct Writing 3D

Micro-/Nano-Lithography. Polymers

2021, 13, 872. https://doi.org/

$10.3390 /$ polym 13060872

Academic Editor: Eva Blasco

Received: 11 February 2021

Accepted: 8 March 2021

Published: 12 March 2021

Publisher's Note: MDPI stays neutral with regard to jurisdictional claims in published maps and institutional affiliations.

Copyright: (c) 2021 by the authors. Licensee MDPI, Basel, Switzerland. This article is an open access article distributed under the terms and conditions of the Creative Commons Attribution (CC BY) license (https:// creativecommons.org/licenses/by/ $4.0 /)$

\begin{abstract}
The use of renewable sources for optical 3D printing instead of petroleum-based materials is increasingly growing. Combinations of photo- and thermal polymerization in dual curing processes can enhance the thermal and mechanical properties of the synthesized thermosets. Consequently, thiol-ene/thiol-epoxy polymers were obtained by combining UV and thermal curing of acrylated epoxidized soybean oil and epoxidized linseed oil with thiols, benzene-1,3-dithiol and pentaerythritol tetra(3-mercaptopropionate). Thiol-epoxy reaction was studied by calorimetry. The changes of rheological properties were examined during UV, thermal and dual curing to select the most suitable formulations for laser direct writing (LDW). The obtained polymers were characterized by dynamicmechanical thermal analysis, thermogravimetry, and mechanical testing. The selected dual curable mixture was tested in LDW 3D lithography for validating its potential in optical micro- and nanoadditive manufacturing. The obtained results demonstrated the suitability of epoxidized linseed oil as a biobased alternative to bisphenol A diglycidyl ether in thiol-epoxy thermal curing reactions. Dual cured thermosets showed higher rigidity, tensile strength, and Young's modulus values compared with UV-cured thiol-ene polymers and the highest thermal stability from all prepared polymers. LDW results proved their suitability for high resolution 3D printing-individual features reaching an unprecedented $100 \mathrm{~nm}$ for plant-based materials. Finally, the biobased resin was tested for thermal post-treatment and $50 \%$ feature downscaling was achieved.
\end{abstract}

Keywords: dual curing; optical 3D printing; laser direct writing; click reactions; thiol-ene; thiol-epoxy; linseed oil; soybean oil; biobased polymer

\section{Introduction}

Laser direct writing (LDW) is a progressive 3D printing technology, which enables production of three-dimensional micro- and nanostructures with variable architectures [1] LDW is widely applied in polymer additive manufacturing due to its flexibility [2] and precise spatial and lateral resolution [3]. The technique is already routinely used in microoptics, microelectronics, as well as biomedicine for the polymer-based device fabrication [4]. In polymer additive manufacturing, (meth)acrylate and epoxy monomers has been widely used for optical 3D printing (O3DP) [5]. A promising way to enhance the thermal-mechanical properties of polymers is to combine similar or different stimuli such as temperature or UV light in dual curing process [6,7]. Thus, the dual curing process could be adapted for O3DP technologies. Recently, thermal post curing of acrylate resins was tested in LDW, which was found to facilitate the high property reproducibility that is essential for any application [8]. Additionally, dual curing stereolithographic resins from petroleum-based acrylate and epoxy monomers were formulated and presented as 
suitable for producing materials with different shape and size [9-11]. This area is still largely unexplored as limited amount of publications have been published so far [12].

Click reactions have been used in polymer science due to high reaction rates, oxygen and water insensitiveness, possibility to be initiated either thermally or photochemically [13]. Thiol-click reactions, including thiol-ene and thiol-epoxy click reactions, are the most notable in the last years for preparation of linear, branched and crosslinked polymers [14]. In thiol-ene click reactions of acrylates, not only step-growth thiol-ene copolymerization, but also chain-growth homopolymerization of acrylate can occur, consequently thiols remain partially unreacted [6]. This performance under stoichiometric reaction conditions may help to increase the cross-linking density, glass transition temperature and mechanical properties of the resulting polymers. Additionally, unreacted groups can be controlled on purpose to get partially cross-linked polymer, or second polymerization reaction can be applied to get fully cured material [7]. Thiol-ene cross-linked polymers have been used in adhesives, coatings, biomedical, and electronic packaging materials [15]. Usually, thiol-ene polymers are prepared from petroleum-based materials, such as bisphenol A diallyl ether, diallyl bisphenol A or bisphenol S diallyl ether [16]. The starting compound bisphenol $\mathrm{A}$ is used in the manufacturing of plastic food and paper consumer products [17]. However, bisphenol A is considered to cause endocrine, metabolic diseases [18,19] and pollutes water [20]. Therefore, researchers are interested in the replacement of bisphenol by monomers obtained from renewable resources. Environmentally friendly materials, such as isosorbide [21], eugenol [22,23], lignin [24], vanillin [25,26], and vegetable oils [27-29] have been already used for thiol-ene click reactions.

Thiol-epoxy click reaction has been widely used for the preparation of adhesives, highperformance coatings, composites [30], hydrogels [31], and shape memory materials [32]. The curing of epoxy resins with thiols is attractive due to the high yield and good mechanical properties of the obtained polymers [33]. The adequate curing temperatures can be achieved by using basic catalysts [34], such as 1-methylimidazole [35], showing no activity under normal conditions and becoming active through external stimulation [36]. About $75 \%$ of epoxy resins production in the current market belongs to bisphenol A diglycidyl ether (DGEBA) [37]. Researchers are interested in the replacement of DGEBA by epoxides obtained from renewable resources. Natural phenolic compounds such as tannins [38-40], terpenes, cardanols [41], vanillin [42], eugenol [43-46], and phloroglucinol [47] are commonly used as a substitute for DGEBA due to their rigid structures [48]. Additionally, one of the alternative options is vegetable oils as they are cheap, available in large quantities, and easily modifiable [37]. Ester groups and double bonds can be chemically modified and new functional groups can be introduced in order to prepare polymers with a broad range of properties, e.g., flexibility, adhesion, resistance to water and chemicals [49]. Vegetable oils are also attractive for polymer synthesis due to their low toxicity and higher biodegradability $[50,51]$. However, long aliphatic chains lead to an excessive flexibility and too low glass transition temperatures [52]. For this reason, aromatic compounds could be used as comonomers for the preparation of polymers from natural oils due to their stability and toughness [53]. Epoxidized oils are also used as substitutes or modifiers for DGEBA [54-57], but there is still little information about the replacement of DGEBA in thiol-epoxy reactions. Epoxidized linseed, soybean, and olive oils were only incorporated into thiol-epoxy networks where DGEBA was also used [58].

After considering health and pollution issues of bisphenol A, advantages of vegetable oils, click reactions, and dual curing, the preparation of vegetable oil-based thiolene/thiol-epoxy resins that could be used in LDW was chosen. In this study, acrylated epoxidized soybean oil (AESO) and epoxidized linseed oil (ELO) were selected as biobased monomers for thiol-ene, thiol-epoxy, and dual curing with commercially available thiols, benzene-1,3-dithiol (1,3BDT) and pentaerythritol tetra(3-mercaptopropionate) (PETMP) (Figure 1). Non-stoichiometric thiol-ene reactions were chosen to form polymers with the higher amount of the flexible thioether bonds and thus to obtain more ductile and less brittle polymers. Curing kinetics of thiol-ene, thiol-epoxy, and dual curing processes 
with ethyl (2,4,6-thimethylbenzoyl) phenyl phosphinate (TPOL) as photoinitiator and 1methylimidazole (1MI) as catalyst were examined by rheological tests. Thermomechanical, thermal stability studies, and mechanical testing of the resulting polymers were carried out. Furthermore, two thiol-ene/thiol-epoxy dual curable formulations were investigated for LDW and evaluated for their applicability as materials for the micro- and nano-scale resolution 3D rapid prototyping. A thermal treatment was performed in order to test their sintering applicability.

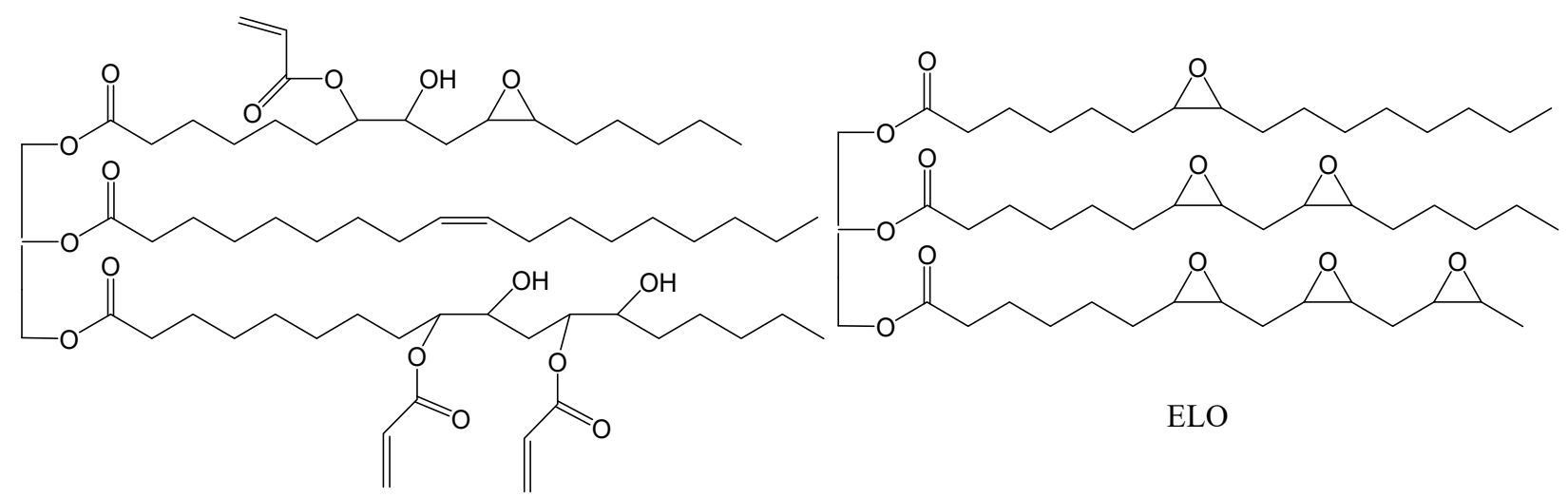

AESO<smiles>Sc1cccc(S)c1</smiles>

$1,3 \mathrm{BDT}$<smiles>O=C(CCS)OCC(COC(=O)CCS)(COC(=O)CCS)COC(=O)CCS</smiles>

PETMP<smiles>CCOP(=O)(C(=O)c1c(C)cc(C)cc1C)c1ccccc1</smiles>

TPOL<smiles>Cn1ccnc1</smiles>

$1 \mathrm{MI}$

Figure 1. Chemical structures of acrylated epoxidized soybean oil (AESO), epoxidized linseed oil (ELO), benzene-1,3-dithiol (1,3BDT), pentaerythritol tetra(3-mercaptopropionate) (PETMP), ethyl (2,4,6-thimethylbenzoyl) phenyl phosphinate (TPOL), and 1-methylimidazole (1MI).

\section{Materials and Methods}

\subsection{Materials}

Acrylated epoxidized soybean oil (AESO, an average number of acryloyl groups per molecule 2.7 and 0.3 of epoxide groups), benzene-1,3-dithiol (1,3BDT), pentaerythritol tetra(3-mercaptopropionate) (PETMP), 1-methylimidazole (1MI), and 4-methyl-2pentanone were purchased from Sigma-Aldrich (Darmstadt, Germany). Epoxidized linseed oil (ELO, having an average number of 6 epoxy groups per molecule) was purchased from Chemical Point (Oberhaching, Germany). Photoinitiator ethyl(2,4,6-thimethylbenzoyl) phenyl phosphinate (TPOL) was purchased from Fluorochem (Hadfield, Derbyshire, UK). All materials were used as received.

\subsection{Rheometry}

Rheological characterization tests were carried out with different thiol-ene and thiolepoxy resins (Table 1). The mixtures of AESO and 1,3BDT or PETMP (thiol-ene resins, AESO with 1,3BDT named as 100A and AESO with PETMP named as 100C), as well as the mixtures of ELO and 1,3BDT or PETMP (thiol-epoxy resins, ELO with 1,3BDT named as $100 \mathrm{~B}$ and ELO with PETMP named as 100D) were prepared and mixed together by different ratio $(75 / 25,50 / 50$ and $25 / 75$ of wt.\%). A total of 3 mol.\% of TPOL as photoinitiator was used for resins 100A, 100C and their mixtures [59]. In total, $5 \mathrm{phr}$ (parts per hundred of total mixture) of 1MI as catalyst was used for resins 100B, 100D and their mixtures. MCR302 rheometer from Anton Paar (Graz, Austria) equipped with the plate/plate measuring 
system with Peltier-controlled temperature chamber with the glass plate (diameter of $38 \mathrm{~mm}$ ) and the top plate PP07 (diameter of $15 \mathrm{~mm}$ ) was used for rheological measurements. The UV curing procedure of resins $100 \mathrm{~A}$ and $100 \mathrm{C}$ were carried out with shear mode with a frequency of $10 \mathrm{~Hz}$ and a strain of $0.3 \%$. The samples were irradiated at room temperature $\left(25.6 \pm 2.6^{\circ} \mathrm{C}\right)$ by UV/Vis radiation in a wavelength range of $250-450 \mathrm{~nm}$ through the glass plate of the temperature chamber using a UV/Vis spot curing system OmniCure S2000, Lumen Dynamics Group Inc. (Mississauga, ON, Canada). The intensity of the irradiation was $9.3 \mathrm{~W} \mathrm{~cm}^{-2}$ (high pressure $200 \mathrm{~W}$ mercury vapor short arc). The thermal curing of resins $100 \mathrm{~B}$ and $100 \mathrm{D}$ was carried out at $150{ }^{\circ} \mathrm{C}$ for $1 \mathrm{~h}$ with a frequency of $1 \mathrm{~Hz}$ and a strain of $1 \%$. Thiol-ene and thiol-epoxy resins $(75 / 25,50 / 50$ and $25 / 75$ of wt. $\%)$ were cured by combining UV and thermal curing. The measuring gap was set to $0.1 \mathrm{~mm}$ for all cases. The gel point $\left(t_{g e l}\right)$ was determined as the cross-over point of storage $\left(G^{\prime}\right)$ and loss $\left(G^{\prime \prime}\right)$ modulus.

Table 1. Composition and viscosity of prepared formulations.

\begin{tabular}{cccccccc}
\hline Resin * & Thiol & $\begin{array}{c}\text { Amount of } \\
\text { AESO, (wt.\%) }\end{array}$ & $\begin{array}{c}\text { Amount of } \\
\text { ELO, (wt.\%) }\end{array}$ & $\begin{array}{c}\text { Amount of } \\
\text { thiol, (wt.\%) }\end{array}$ & $\begin{array}{c}\text { Amount of } \\
\text { TPOL, (wt.\%) }\end{array}$ & $\begin{array}{c}\text { Amount of } \\
\text { 1MI, (wt.\%) }\end{array}$ & $\begin{array}{c}\text { Viscosity } \boldsymbol{\eta} \text {, } \\
\text { Pa.s }\end{array}$ \\
\hline 100A & & 88.16 & 0 & 10.53 & 1.31 & 0 & $17.26 \pm 0.40$ \\
75A/25B & & 65.56 & 17.03 & 15.26 & 0.98 & 1.17 & $13.32 \pm 0.23$ \\
50A/50B & 1,3BDT & 43.26 & 33.75 & 19.98 & 0.58 & 2.43 & $3.71 \pm 0.69$ \\
25A/75B & & 21.43 & 50.16 & 24.51 & 0.29 & 3.61 & $0.54 \pm 0.01$ \\
100B & & 0 & 66.41 & 29.01 & 0 & 1.00 & $0.12 \pm 0.01$ \\
\hline 100C & & 81.57 & 0 & 17.43 & 0.75 & 1.17 & $4.03 \pm 0.02$ \\
75C/25D & & 60.61 & 13.93 & 23.54 & 0.49 & 2.42 & $2.10 \pm 0.09$ \\
50C/50D & PETMP & 40.00 & 27.67 & 29.42 & 0.25 & 3.62 & $1.90 \pm 0.10$ \\
25C/75D & & 19.80 & 41.09 & 35.24 & 0 & 4.58 & $0.55 \pm 0.02$ \\
100D & & 0 & 54.20 & 41.22 & & 0.02 \\
\hline
\end{tabular}

* A—thiol-ene resin of AESO with 1,3BDT; B-thiol-epoxy resin of ELO with 1,3BDT; C-thiol-ene resin of AESO with PETMP; D—thiolepoxy resin of ELO with PETMP; 100, 75, 50, 25-amount (wt.\%) of thiol-ene (A or C) and/or thiol-epoxy (B or D) resin in the mixture.

The viscosity $(\eta)$ of all formulations was measured with a MCR302 rheometer from Anton Paar (Graz, Austria) equipped with a steel parallel plate (top plate diameter of $15 \mathrm{~mm})$ measuring system at room temperature $\left(25^{\circ} \mathrm{C}\right)$. The measuring gap was set to $0.1 \mathrm{~mm}$.

\subsection{Preparation of Cross-Linked Polymers}

Thiol-ene cross-linked polymers named as 100A and 100C were obtained by photopolymerization of AESO with 1,3BDT or PETMP (acryl/SH groups 1:1) using $3 \mathrm{~mol} . \%$ of TPOL as photoinitiator under a UV lamp (Helios Italquartz, model GR.E 500 W, Milan, Italy) with UV/Vis light at intensity of $310 \mathrm{~mW} / \mathrm{cm}^{2}$ for $10 \mathrm{~min}$. Thiol-epoxy cross-linked polymers 100B and 100D were obtained by thermal polymerization of ELO with 1,3BDT or PETMP (epoxy/SH groups 1:1) using $5 \mathrm{phr}$ of $1 \mathrm{MI}$ as a catalyst. The curing process was carried out at $150{ }^{\circ} \mathrm{C}$ for $3 \mathrm{~h}$. Thiol-ene/thiol-epoxy polymers $75 \mathrm{~A} / 25 \mathrm{~B}$ (75 wt. $\%$ of thiol-ene mixture of AESO with 1,3BDT and $25 \mathrm{wt} . \%$ of thiol-epoxy mixture of ELO with 1,3BDT) and 75C/25D (75 wt.\% of thiol-ene of AESO with PETMP and $25 \mathrm{wt} . \%$ of thiol-epoxy resin of ELO with PETMP) were prepared by combining UV and thermal curing at $150{ }^{\circ} \mathrm{C}$ for $1 \mathrm{~h}$ when the sample reached the temperature. All polymers were prepared using $70 \mathrm{~mm} \times 10 \mathrm{~mm} \times 1 \mathrm{~mm}$ Teflon molds.

\subsection{Characterization Techniques}

The evolution of thermal curing process of resins $100 \mathrm{C}$ and 100D was examined by calorimetric studies on a A Mettler DSC-821 apparatus (Mississauga, ON, Canada). Curing formulations were prepared by mixing ELO and 1,3BDT or PETMP (epoxy /thiol groups 1:1) using 1-5 phr of $1 \mathrm{MI}$ as a catalyst. Samples of $10 \mathrm{mg}$ were analyzed under non-isothermal conditions in the temperature range from $30^{\circ} \mathrm{C}$ to $250{ }^{\circ} \mathrm{C}$ at a heating rate of $10^{\circ} \mathrm{C} / \mathrm{min}$ 
under nitrogen atmosphere (nitrogen flow rate $100 \mathrm{~mL} / \mathrm{min}$ ) as described previously [28]. The reaction enthalpy $(\Delta h)$ was integrated from the calorimetric heat flow signal $(d h / d t)$ using a straight baseline with the help of the STARe software.

A Perkin-Elmer Spectrum BX II FT-IR spectrometer (Llanstrisant, UK) was used to record IR spectra of cross-linked polymers. The reflection was measured during the test. The range of wavenumber was $(650-4000) \mathrm{cm}^{-1}$.

Dynamic-mechanical thermal analysis (DMTA) was performed in a tensile mode using MCR rheometer from Anton Paar (Graz, Austria). Temperature was ramped from $0{ }^{\circ} \mathrm{C}$ to $110{ }^{\circ} \mathrm{C}$ at a rate of $2{ }^{\circ} \mathrm{C} / \mathrm{min}$. Tests were performed with the samples of the following size: $40 \mathrm{~mm} \times 10 \mathrm{~mm} \times 1 \mathrm{~mm}$. Glass transition temperature $\left(T_{g}\right)$ was defined by the maximum peak of $\tan \delta$ curve. The rubbery modulus $\left(E_{\mathrm{r}}\right)$ was determined at $T_{g}+50{ }^{\circ} \mathrm{C}$ from the storage modulus curves.

Cross-linking density $\left(v_{e}\right)$ of polymers was calculated according to the Flory's rubber elasticity theory [60]:

$$
v_{e}=\frac{E^{\prime}}{3 \cdot R \cdot T}
$$

where $v_{e}$ is the cross-linking density $\left(\mathrm{mol} / \mathrm{m}^{3}\right) ; E^{\prime}$ is the apparent rubbery modulus obtained by DMTA from storage modulus curve $(\mathrm{Pa}) ; R$ is the universal gas constant $(8.314 \mathrm{~J} / \mathrm{K} / \mathrm{mol})$; $T$ is the absolute temperature $(\mathrm{K})$.

Thermal decomposition temperature at the 5\% weight loss $\left(T_{\text {dec. }-5 \%}\right)$ and the char yield after thermal degradation of the cross-linked polymers were determined by thermogravimetric analysis (TGA). The measurements were performed on a TA Instruments Q50 apparatus (New Castle, DE, USA) in the temperature range from room temperature to $700{ }^{\circ} \mathrm{C}$ at a heating rate of $20{ }^{\circ} \mathrm{C} / \mathrm{min}$ under $\mathrm{N}_{2}$ atmosphere (nitrogen flow rate $100 \mathrm{~mL} / \mathrm{min}$ ).

Mechanical properties of cross-linked polymers were estimated by tensile test on a BDO-FB0.5TH (Zwick/Roell) (Kennesaw, GA, USA) testing machine at $22{ }^{\circ} \mathrm{C}$ using the ASTMD-638-V standard. Strain rate of $1 \mathrm{~mm} / \mathrm{min}$ was used in all cases. Mechanical testing was performed on the dog bone-shaped samples to determine elongation at break, tensile strength, and Young's modulus. The average values were taken from at least three samples.

LDW 3D lithography was performed employing an ultrafast Pharos laser (515 nm, 300 fs, 200 kHz, Light Conversion Ltd., Vilnius, Lithuania), $63 \times \mathrm{NA}=1.4$ objective, and combined movements of the linear stages and galvano-scanners. Resolution bridges (RB) method was used to investigate custom-made resin suitability for LDW [61]. The RB model consisted of two rectangle-shaped columns with a width of $25 \mu \mathrm{m}$, a length of $60 \mu \mathrm{m}$, and a height of $25 \mu \mathrm{m}$, which were separated by a gap of $35 \mu \mathrm{m}$. The five straight lines were formed in the gaps perpendicularly to the long edges of the columns. Each line was polymerized from a single laser beam scan. RB were obtained with different longitudinal and lateral sizes by varying the laser power $(P)$ from 0.01 to $0.15 \mathrm{~mW}$, which corresponded to the light intensity $(I)$ at the sample $\left(0.03-0.4 \mathrm{TW} / \mathrm{cm}^{2}\right)$, and the scanning velocity $(v)$ from 1 to $4 \mathrm{~mm} / \mathrm{s}$. Additionally, manufacturing of bulky arc-type objects was presented. It was made of two $25 \times 25 \mu \mathrm{m}^{2}$ columns with a varied height from 5 to $20 \mu \mathrm{m}$ and distance between the columns from 25 to $100 \mu \mathrm{m}$. The columns were connected with a continuous arc on the top. During the fabrication, the resin was placed between two glass slides, creating a layer of $80-100 \mu \mathrm{m}$ of the resin as was already described previously [62]. After the exposure, the samples were developed in 4-methyl-2-pentanone for $30 \mathrm{~min}$, removing the uncured resin and leaving only the formed structures on the substrate. The fabricated structures were dried with a critical point dryer K850 (Quorum Technologies, East Sussex, UK), sputtered with $10 \mathrm{~nm}$ silver layer employing a rotary pumped coater 150R S (Quorum Technologies, East Sussex, UK), and characterized using a scanning electron microscope (SEM, Prisma E, Eindhoven, The Netherlands). For heat treatment, a high temperature hot plate of titanium PZ 28-3T and Programmer PR 5-3T were used (Harry Gestigkeit GmbH, Düsseldorf, Germany). The sample of RB was heated twice: for one hour at $225^{\circ} \mathrm{C}$ and later for one hour at $300{ }^{\circ} \mathrm{C}$. After each heat treatment the sample was removed from the 
hot plate immediately and left in room temperature for couple of minutes to cool down. Then the sample was recoated with a $10 \mathrm{~nm}$ silver layer and characterized using SEM.

\section{Results}

\subsection{Study of Thermal Thiol-Epoxy Curing Process}

The thiol-epoxy curing process was examined by calorimetric studies to determine the required amount of catalyst $1 \mathrm{MI}$. The DSC thermograms corresponding to thermal curing of $100 \mathrm{~B}$ and $100 \mathrm{D}$ formulations with $1-5 \mathrm{phr}$ of $1 \mathrm{MI}$ are shown in Figure 2. It was determined that $1,3 \mathrm{BDT}$ was the more reactive thiol with the lower activation temperature due to the higher acidity of the thiophenols than the thiols and the higher nucleophilicity of the thiophenolate anion compared to PETMP. The reaction of ELO with PETMP started at about $140{ }^{\circ} \mathrm{C}$ and was finished at a high temperature, which indicated that the reactivity was rather low. Additionally, the shape of the curves was wider compared to the narrower and higher curves corresponding to the curing of ELO with 1,3BDT, which indicated the faster reaction.

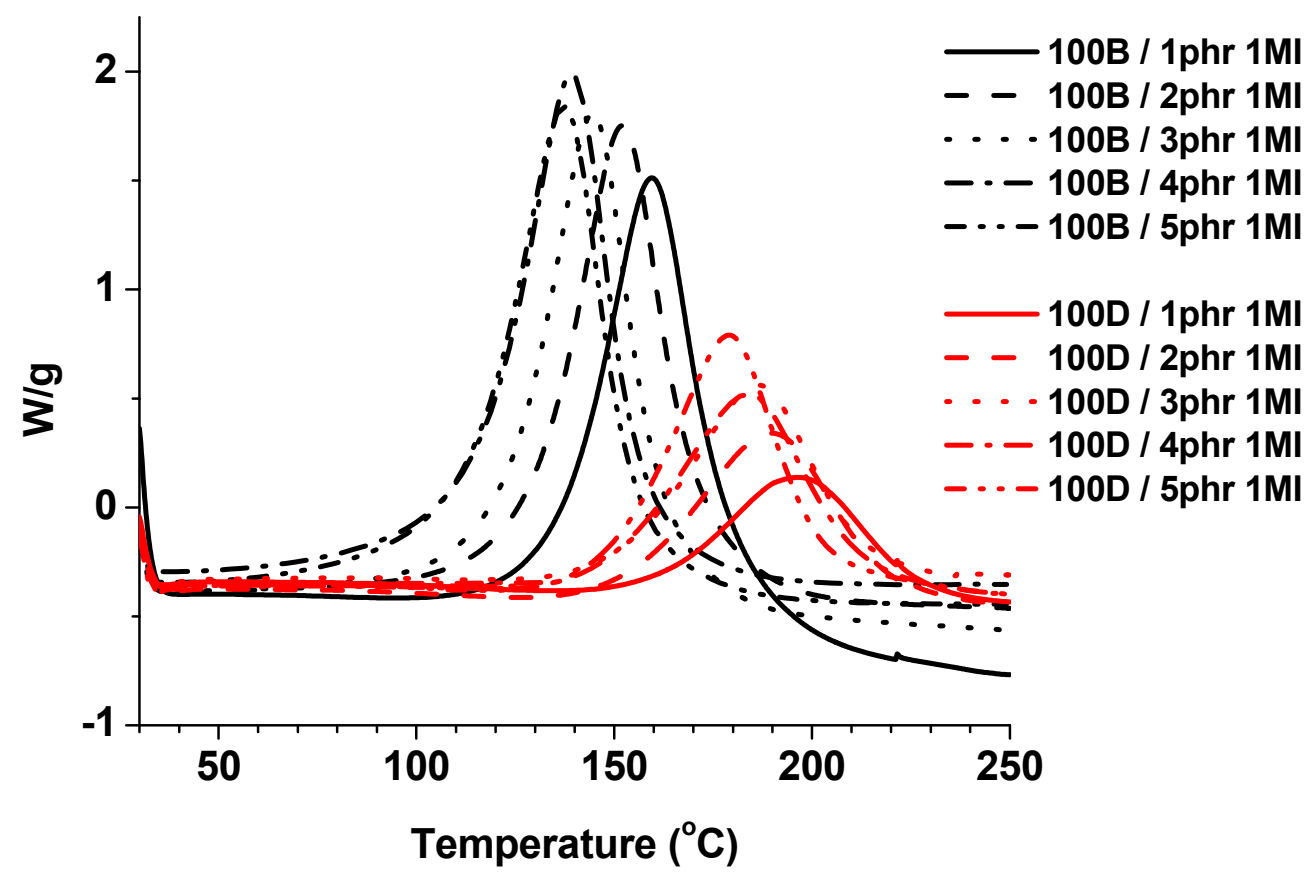

Figure 2. Calorimetric curves corresponding to the curing of ELO with different thiols using 1MI as catalyst.

Calorimetric data of the curing of ELO resins with different thiols and 1MI as the catalyst are listed in Table 2. The biggest amount of heat was released using $5 \mathrm{phr}$ of $1 \mathrm{MI}$ in the resins of $100 \mathrm{~B}$ and $100 \mathrm{D}(443.8 \mathrm{~J} / \mathrm{g}$ and $256.3 \mathrm{~J} / \mathrm{g}$, respectively) leading to the highest curing enthalpy by epoxy equivalent $(107.8 \mathrm{~kJ} / \mathrm{eq}$ and $76.5 \mathrm{~kJ} / \mathrm{eq}$, respectively). This indicated that the heat released by epoxy equivalent was higher when the amount of catalyst was increased. According to these results, $5 \mathrm{phr}$ of $1 \mathrm{MI}$ was used in the resins of 100B and 100D. 
Table 2. Calorimetric data of the curing of epoxidized linseed oil (ELO) with benzene-1,3-dithiol (1,3BDT) and pentaerytritol tetrakis (3-mercaptopropionate) (PETMP) containing different amounts of 1-methylimidazole (1MI).

\begin{tabular}{cccc}
\hline Resin & Proportion of $\mathbf{1 M I}\left(\mathbf{p h r}^{\mathbf{1}}\right)$ & $\boldsymbol{\Delta} \boldsymbol{h}^{\mathbf{2}} \mathbf{( J / g )}$ & $\boldsymbol{\Delta} \boldsymbol{h}^{\mathbf{3}} \mathbf{( k J / e q )}$ \\
\hline 1 & 400.1 & 93.5 \\
\multirow{3}{*}{ 100B } & 2 & 405.6 & 95.8 \\
& 3 & 409.3 & 97.5 \\
& 5 & 427.4 & 102.9 \\
& 1 & 443.8 & 107.8 \\
\hline \multirow{2}{*}{ 100D } & 1 & 139.4 & 39.7 \\
& 3 & 190.0 & 57.1 \\
& 4 & 207.0 & 60.6 \\
& 5 & 225.6 & 66.7 \\
\hline
\end{tabular}

${ }_{1}^{1}$ phr-parts per hundred of the monomer mixture; ${ }^{2}$ curing enthalpy measured in a DSC scan at $10{ }^{\circ} \mathrm{C} / \mathrm{min}$; 3 curing enthalpy by epoxy equivalent of the initial mixture.

\subsection{Monitoring Cross-Linking Kinetics by Rheometry}

Rheometry was used to monitor the changes of rheological properties of the resins during UV, thermal and dual curings. Rheometry data of the resins are collected in Table 3. Thiol-ene photocross-linking of the resin 100C containing PETMP as a thiol was faster than that of the resin 100A containing 1,3BDT, as the gel point was reached faster $(2 \mathrm{~s}$ vs. $3.5 \mathrm{~s})$ and the obtained polymer was more rigid according to the storage modulus (3.79 MPa and 1.56 MPa). The opposite results were obtained with thiol-epoxy thermally cured resins $100 \mathrm{~B}$ and $100 \mathrm{D}$ as thermal polymerization is a slower process compared to photopolymerization. Consequently, by decreasing the amount of thiol-epoxy part in the resin, the gel point was reached faster and rheological characteristics were higher. Storage modulus $G^{\prime}$ curves versus curing time of the dual cured polymers are shown in Figure 3. During the first curing stage, when UV irradiation was applied, $G^{\prime}$ of the resins $75 \mathrm{~A} / 25 \mathrm{~B}$, $75 \mathrm{C} / 25 \mathrm{D}$, and $50 \mathrm{C} / 50 \mathrm{D}$ increased, while the other resins remained in liquid form. During intermediate stage when the temperature was ramped to $150^{\circ} \mathrm{C}, \mathrm{G}^{\prime}$ of three mentioned polymers started to decrease, indicating glass transition of thiol-ene polymer. After that, $G^{\prime}$ started to increase, demonstrating the starting of the thiol-epoxy reaction. $G^{\prime}$ of the other resins: 50A/50B, 25A/75B, and $25 \mathrm{C} / 75 \mathrm{D}$ started to increase, after reaching a certain temperature, showing the formation of cross-linked structure by the thiol-epoxy process. During the second curing stage when a constant temperature of $150{ }^{\circ} \mathrm{C}$ was applied, $G^{\prime}$ of all resins increased and reached a plateau. The resins $75 \mathrm{~A} / 25 \mathrm{~B}$ and $75 \mathrm{C} / 25 \mathrm{D}$ with the lowest thiol-epoxy part were selected for further investigation of properties, since they were solid after the first curing stage which is essential for LDW and they obtained the highest values of $G^{\prime}$. The highest viscosity of the resins (Table 1) was also an essential factor for the selection of resins for LDW.

Table 3. Rheological characteristics of vegetable oil-based thiol-ene/thiol-epoxy mixtures.

\begin{tabular}{ccccc}
\hline Resin & Storage Modulus $G^{\prime}(\mathbf{M P a})$ & Loss Modulus $\boldsymbol{G}^{\prime \prime}(\mathbf{k P a})$ & Complex Viscosity $\boldsymbol{\eta}^{*}(\mathbf{M P a} \cdot \mathbf{s})$ & Gel Point $\boldsymbol{t}_{\text {gel }}(\mathbf{s})$ \\
\hline 100A & $1.56 \pm 0.05$ & $257.72 \pm 27.04$ & $25.15 \pm 0.85$ & $3.5 \pm 0.5$ \\
$75 \mathrm{~A} / 25 \mathrm{~B}$ & $2.44 \pm 0.00$ & $10.25 \pm 1.38$ & $38.85 \pm 0.01$ & $7.0 \pm 0.0$ \\
50A/50B & $1.30 \pm 0.10$ & $2.98 \pm 0.09$ & $20.55 \pm 1.45$ & $1340.1 \pm 35.7$ \\
$25 \mathrm{~A} / 75 \mathrm{~B}$ & $3.15 \pm 0.00$ & $60.58 \pm 0.00$ & $50.10 \pm 0.00$ & $1390.2 \pm 0.0$ \\
100B & $5.19 \pm 0.60$ & $106.77 \pm 0.61$ & $82.55 \pm 9.55$ & $786.6 \pm 15.6$ \\
\hline 100C & $3.79 \pm 0.30$ & $1415 \pm 385$ & $64.50 \pm 6.60$ & $2.0 \pm 0.0$ \\
$75 \mathrm{C} / 25 \mathrm{D}$ & $3.96 \pm 0.00$ & $12.56 \pm 0.00$ & $63.03 \pm 0.00$ & $2.0 \pm 0.0$ \\
50C/50D & $3.87 \pm 0.00$ & $11.37 \pm 0.00$ & $61.62 \pm 0.00$ & $2.0 \pm 0.0$ \\
25C/75D & $2.70 \pm 0.00$ & $9.94 \pm 0.00$ & $52.90 \pm 0.00$ & $1692.6 \pm 0.0$ \\
100D & $3.36 \pm 0.29$ & $25.80 \pm 0.00$ & $53.35 \pm 4.55$ & $1170.0 \pm 0.0$ \\
\hline
\end{tabular}




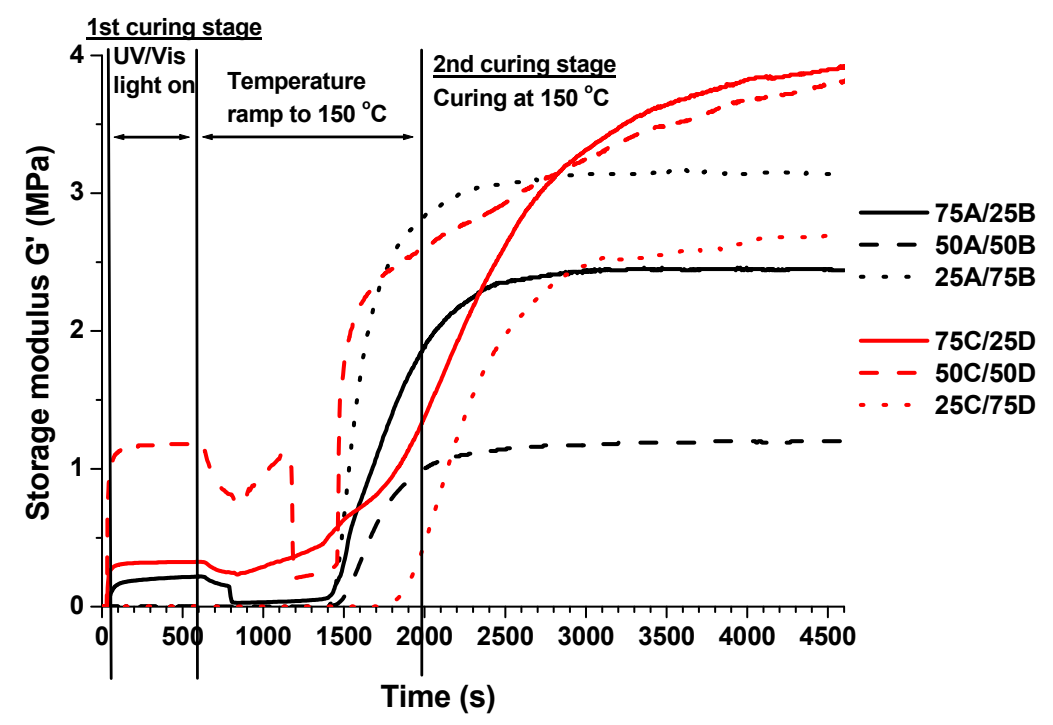

Figure 3. Storage modulus versus curing time of dual cured vegetable oil-based resins.

\subsection{Characterization of Cross-Linked Polymer Structure}

Cross-linked polymers were characterized by FT-IR spectroscopy, which spectra showed the characteristic absorption signals corresponding to their chemical structure (Figure 4). The disappearance of S-H group absorption signal, which was present at $2562 \mathrm{~cm}^{-1}$ and $2565 \mathrm{~cm}^{-1}$ in the spectra of 1,3BDT and PETMP, was observed in the spectra of the corresponding cross-linked polymers 75A/25B and 75C/25D (Figure 4a). The signal of $\mathrm{C}=\mathrm{C}$ at $1636 \mathrm{~cm}^{-1}$ in the spectrum of AESO and the signal of epoxy group at $940 \mathrm{~cm}^{-1}$ in the spectrum of ELO disappeared and the most relevant C-S group stretch at $1233 \mathrm{~cm}^{-1}$ appeared in the FT-IR spectra of the cross-linked polymers. In addition, strong absorption signals of C-O-C group at $1151 \mathrm{~cm}^{-1}$ and $1154 \mathrm{~cm}^{-1}$ were observed in FT-IR spectra of both polymers. Figure $4 \mathrm{~b}$ shows that the signal of $\mathrm{S}-\mathrm{H}$ group at about $2570 \mathrm{~cm}^{-1}$ is visible after UV irradiation and disappears after thermal curing when polymer is completely cured.

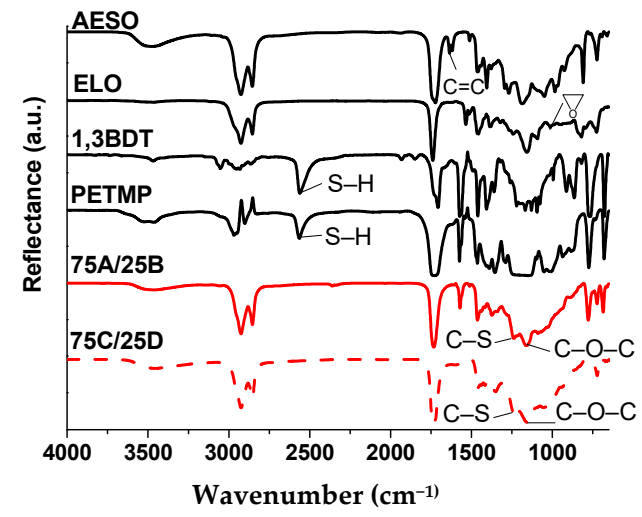

(a)

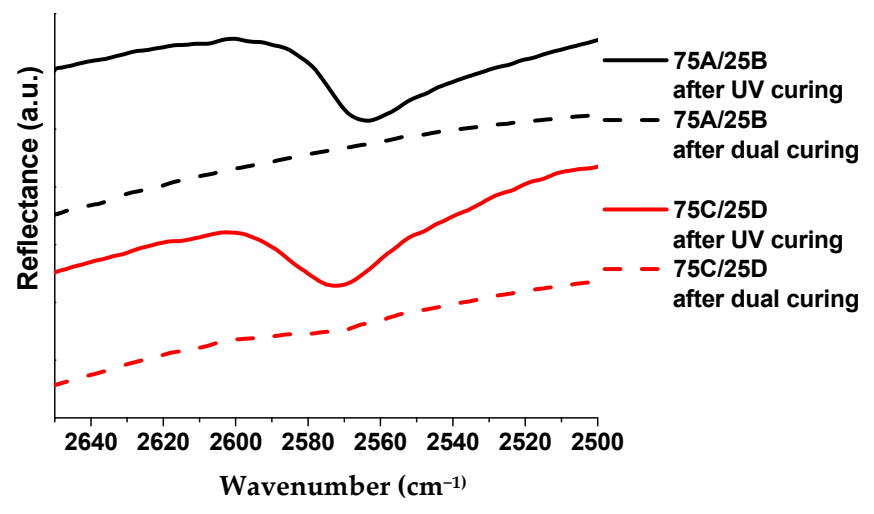

(b)

Figure 4. (a) FT-IR spectra of AESO, ELO, 1,3BDT, PETMP, cross-linked polymers 75A/25B and 75C/25D; (b) FT-IR region corresponding to $\mathrm{S}-\mathrm{H}$ group absorption signal of the resins $75 \mathrm{~A} / 25 \mathrm{~B}$ and $75 \mathrm{C} / 25 \mathrm{D}$ after UV irradiation and after complete curing.

\subsection{Thermal Characterization of the Materials}

Table 4 collects the data obtained by DMTA and TGA analysis. Glass transition temperature $\left(T_{g}\right)$ of photocross-linked thiol-ene polymer $100 \mathrm{~A}\left(-4{ }^{\circ} \mathrm{C}\right)$ with the aromatic fragments of $1,3 \mathrm{BDT}$ was similar to that of the analogous polymer obtained using another photoinitiator $\left(-3^{\circ} \mathrm{C}\right)$ [29]. The $T_{g}$ of the polymer $100 \mathrm{C}$ with the aliphatic fragments of 
PETMP $\left(1{ }^{\circ} \mathrm{C}\right)$ was also similar to that of the analogous polymer $T_{g}\left(-1.3^{\circ} \mathrm{C}\right)$ [27]. The thermally cured thiol-epoxy cross-linked polymer 100B with the aromatic fragments of 1,3BDT showed higher $T_{g}$ than polymer 100D with PETMP fragments $\left(60^{\circ} \mathrm{C}\right.$ and $29^{\circ} \mathrm{C}$, respectively). The $T_{g}$ of polymer $100 \mathrm{D}\left(29^{\circ} \mathrm{C}\right)$ was similar to $T_{g}$ of DGEBA thiol-epoxy polymers with incorporated ELO $\left(25.2-30.4^{\circ} \mathrm{C}\right)$ [58]. The $T_{g}$ of polymer $100 \mathrm{~B}\left(60^{\circ} \mathrm{C}\right)$ was similar to $T_{g}$ of DGEBA and PETMP polymer $\left(59.7-68^{\circ} \mathrm{C}\right)[32,63,64]$.

Table 4. Dynamic mechanical thermal analysis (DMTA) and thermogravimetric analysis (TGA) data.

\begin{tabular}{|c|c|c|c|c|c|}
\hline \multirow{2}{*}{ Polymer } & \multicolumn{3}{|c|}{ DMTA } & \multicolumn{2}{|c|}{ TGA } \\
\hline & $T_{g}{ }^{1}\left({ }^{\circ} \mathrm{C}\right)$ & $E_{r}^{2}(\mathrm{MPa})$ & $v_{e}^{3}\left(\mathrm{~mol} / \mathrm{m}^{3}\right)$ & $T_{\text {dec. }-5 \%}{ }^{4}\left({ }^{\circ} \mathrm{C}\right)$ & Char yield ${ }^{5}(\%)$ \\
\hline 100A & -4 & 3.98 & 479 & 343 & 0.7 \\
\hline $75 \mathrm{~A} / 25 \mathrm{~B}$ & 4 & 5.10 & 614 & 344 & 1.3 \\
\hline 100B & 60 & 6.16 & 742 & 308 & 2.2 \\
\hline 100C & 1 & 5.64 & 679 & 354 & 0.9 \\
\hline $75 \mathrm{C} / 25 \mathrm{D}$ & -4 & 6.38 & 768 & 358 & 1.1 \\
\hline 100D & 29 & 3.92 & 472 & 317 & 2.4 \\
\hline
\end{tabular}

${ }^{1}$ Temperature of the maximum of $\tan \delta$ estimated by DMTA; ${ }^{2}$ Storage modulus in the rubbery state determined at $T_{g}+50{ }^{\circ} \mathrm{C} ;{ }^{3}$ Cross-linking density calculated according to the Flory's rubber elasticity theory; ${ }^{4}$ Temperature at the weight loss of $5 \%$ obtained from TGA curve; ${ }^{5}$ After thermal degradation in $\mathrm{N}_{2}$ atmosphere.

The evolution of $\tan \delta$ versus temperature of the cross-linked polymers with different thiols is shown in Figure 5a. As we can see, the curves of the dual cured polymers 75A/25B and $75 \mathrm{C} / 25 \mathrm{D}$ (with maxima at $4{ }^{\circ} \mathrm{C}$ and $-4{ }^{\circ} \mathrm{C}$ ) are similar to those obtained by UV cured polymers $100 \mathrm{~A}$ and $100 \mathrm{D}\left(-4^{\circ} \mathrm{C}, 1^{\circ} \mathrm{C}\right)$. Only thermally cured thiol-epoxy polymers show a displacement to higher $T_{g}$ and a broadening of the curve. It seems that the lower contribution of the second stage of dual curing ( $75 \% \mathrm{UV}$ and $25 \%$ thermal) leads to a reduced effect on these characteristics. The highest storage modulus in the rubbery state and the highest cross-linking density correspond to the dual cured polymer $75 \mathrm{C} / 25 \mathrm{D}$ $\left(6.38 \mathrm{MPa}\right.$ and $\left.768 \mathrm{~mol} / \mathrm{m}^{3}\right)$ (Table 4$)$. This was probably due to the higher functionality of PETMP compared to 1,3BDT or homopolymerization of AESO that led to the increased degree of cross-linking.

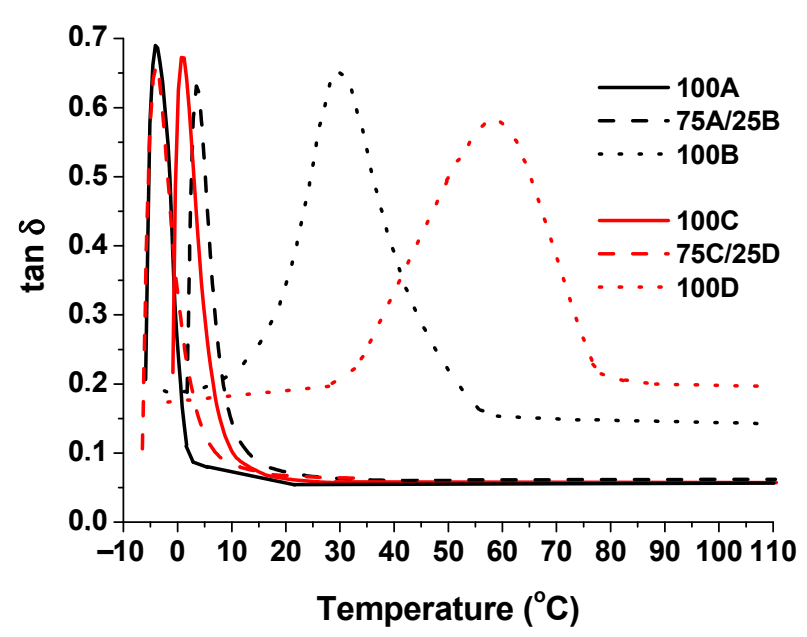

(a)

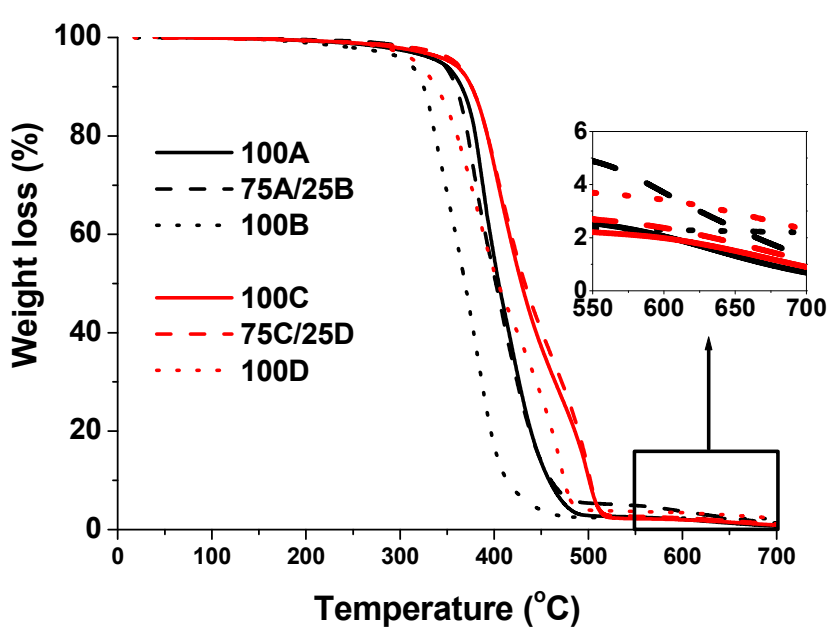

(b)

Figure 5. (a) Tan $\delta$ versus temperature curves of the cross-linked polymers; (b) Thermogravimetric curves of the crosslinked polymers.

The thermal stability of the polymers prepared was evaluated by TGA. Photocrosslinked thiol-ene polymers 100A and 100C showed higher thermal decomposition temperatures at the $5 \%$ weight loss $\left(T_{\text {dec }}-5 \%\right)$ compared to that of the thermally cured thiol-epoxy polymers 
100B and 100D. However, dual cured polymers 75A/25B and 75C/25D showed the highest $T_{\text {dec. }-5 \%}\left(344^{\circ} \mathrm{C}\right.$ and $358{ }^{\circ} \mathrm{C}$, respectively) and intermediary char yield. $T_{\text {dec. }-5 \%}$ of polymer $100 \mathrm{D}\left(317^{\circ} \mathrm{C}\right)$ is similar to $T_{\text {dec }}-5 \%$ of DGEBA and PETMP polymer $\left(330-341^{\circ} \mathrm{C}\right)[63,64]$ and is higher than $T_{d e c}-5 \%$ of DGEBA thiol-epoxy polymers with incorporated ELO $\left(276-301^{\circ} \mathrm{C}\right.$ ) [58]. Thermal degradation of polymers with the fragments of 1,3BDT proceeded in one degradation step (Figure 5b). However, the shape of curves of polymers with the fragments of PETMP had a shoulder at higher temperatures due to ester groups of PETMP. It was observed earlier in the TGA curve of the cross-linked polymer of AESO and PETMP [28].

\subsection{Mechanical Properties}

The data of the mechanical characterization of polymers performed on the dog-boneshaped specimens by tensile test are collected in Table 5. Only polymers obtained by thiol-epoxy curing (100B and 100D) have $T_{g}$ above room temperature and behave as elastic rigid solid polymers. Polymer 100D might not be fully cured as it has the highest elongation at break value. Polymers with the fragments of 1,3BDT are stiffer, have lower ductility, and brittle behavior, as can be seen from elongation at break, tensile strength and Young's modulus values, due to the rigid structure of 1,3BDT. Thermally cured thiol-epoxy polymers 100B and 100D showed the highest values of mechanical characteristics compared to UV cured thiol-ene polymers $100 \mathrm{~A}$ and $100 \mathrm{C}$. Therefore, dual cured polymers $75 \mathrm{~A} / 25 \mathrm{~B}$ and $75 \mathrm{C} / 25 \mathrm{D}$ showed higher values compared with polymers $100 \mathrm{~A}$ and $100 \mathrm{C}$. The tensile strength of ELO-based polymers 100B and 100D (1.44-31.54 MPa) are similar to DGEBA thiol-epoxy polymers with incorporated ELO (8.3-26.4 MPa) [58].

Table 5. Mechanical characteristics of polymers.

\begin{tabular}{cccc}
\hline Polymer & Elongation at Break (\%) & Tensile Strength (MPa) & Young's Modulus (MPa) \\
\hline 100A & $5.75 \pm 0.23$ & $0.65 \pm 0.03$ & $9.53 \pm 4.42$ \\
$75 \mathrm{~A} / 25 \mathrm{~B}$ & $3.26 \pm 0.03$ & $0.91 \pm 0.09$ & $13.46 \pm 1.81$ \\
100B & $1.92 \pm 0.06$ & $31.54 \pm 2.72$ & $2458 \pm 43.90$ \\
100C & $1.95 \pm 0.82$ & $0.82 \pm 0.50$ & $4.00 \pm 2.09$ \\
$75 \mathrm{C} / 25 \mathrm{D}$ & $4.97 \pm 1.11$ & $0.87 \pm 0.01$ & $8.76 \pm 2.22$ \\
100D & $7.03 \pm 1.05$ & $1.44 \pm 0.43$ & $23.3 \pm 0.96$ \\
\hline
\end{tabular}

\subsection{Characterization of $3 D$ Structures Produced by LDW}

Polymer 75C/25D was used for the 3D micro-/nano-printing experiments as it was less reactive, thus unexposed volume did not fully cure itself during the time needed for the laser writing (which was opposite with polymer 75A/25B). The featured findings are demonstrated in Figure 6. In part (a), RB produced at $v=3 \mathrm{~mm} / \mathrm{s}$ with $P=0.11-0.15 \mathrm{~mW}$ are showed with the averaged line width. It was possible to achieve a sub-micro feature size, however a tendency to show how it depends on applied exposure was not clearly distinguished as it was influenced by the material itself, its developing and drying conditions. As depicted in the picture, lines manufactured at lower $P(0.11$ and $0.12 \mathrm{~mW})$ were thicker than the ones produced with higher $P(0.13-0.15 \mathrm{~mW})$, which is a slight increment in exposure dose, yet more sensitive to the individual line formation. These observations can be explained with detailed image of RB at angle of 45 degrees, as shown in Figure 6b. Sometimes two lines might merge to the one making $X$ shape yarn. Often, the thicker bubble-like parts are polymerized within the length of the lines. Lastly, the residual undissolved material, here called "skirt" and shown as the close up in a red dashed rectangle, can be detected underneath the main line. Looking from the top, this "skirt" can be seen and measured, making the line appearance thicker than it is. The artificial structure was not designed to be produced and consisted of additional polymerized material stuck to the directly fabricated line. Despite this, such leftovers of the material can be an advantageous result of the laser writing at higher intensity levels, developing process, and drying at the critical point. As presented in Figure 6c, separate low thickness features down to almost 
$100 \mathrm{~nm}$ can be formed, which are self-supported and show no tension even after ablating the line structure while SEM imaging. Here we demonstrate a line of $103 \mathrm{~nm}$ thickness produced in biobased resins for the very first time, which is currently a record value for it. Previously reported features were of $500 \mathrm{~nm}$ [65] and sub-400 nm [66], respectively. Finally, bulky arc-type objects are displayed in Figure 6d. It reveals that complex architecture structures can be manufactured reproducibly out of polymer $75 \mathrm{C} / 25 \mathrm{D}$, as hanged bulk parts of $100 \mu \mathrm{m}$ length survive even without critical point drying. In summary, the developed plant-based resin was validated for its potential usage in LDW 3D micro-/nanolithography, individual features can reach an unprecedented $100 \mathrm{~nm}$ dimensions, yet some further efforts are needed for optimising material homogeneity to fit industrial demands.

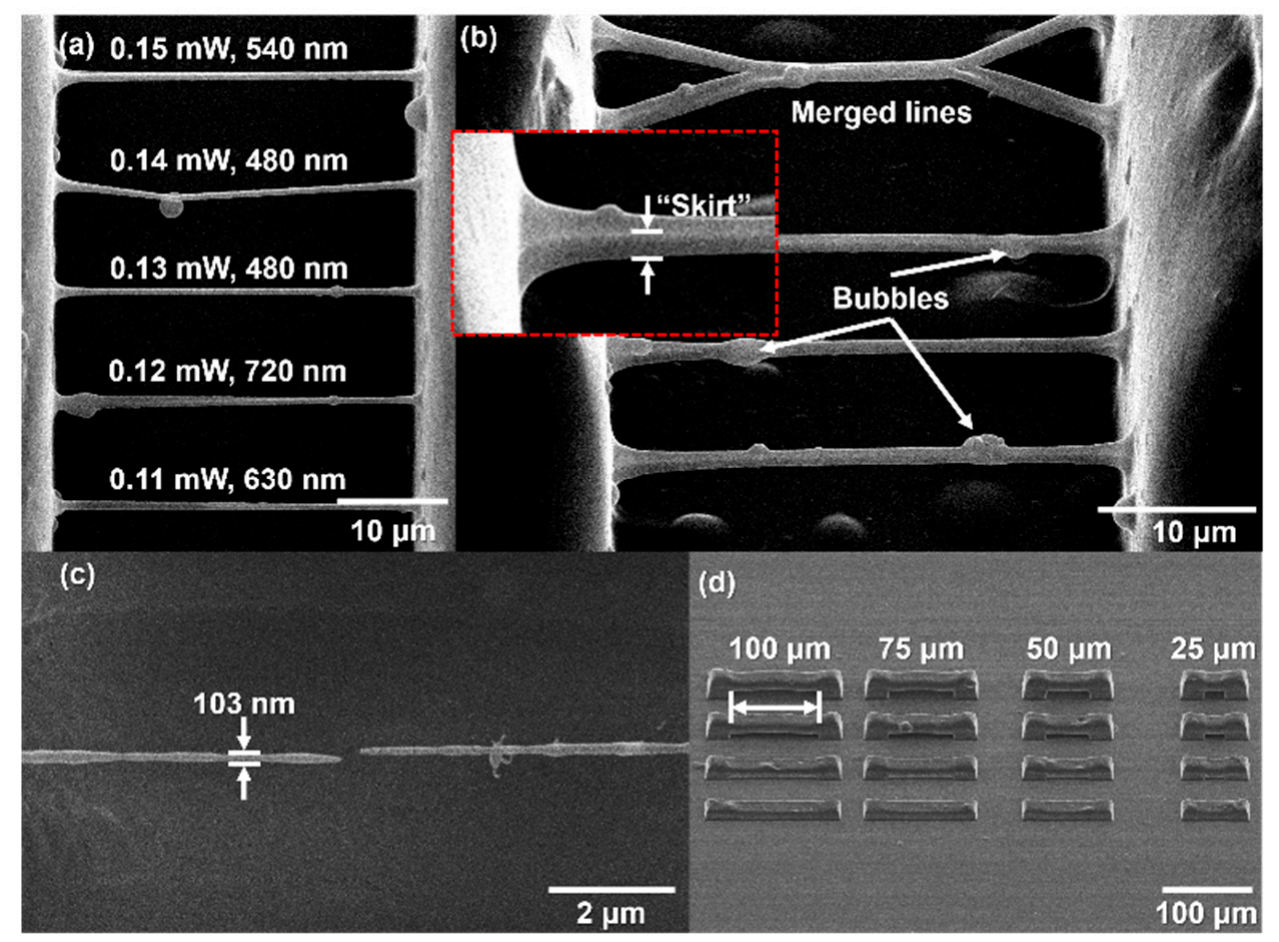

Figure 6. The SEM images of produced objects via laser direct writing (LDW). (a) RB manufactured with $P=0.11-0.15 \mathrm{~mW}\left(I=0.3-0.4 \mathrm{TW} / \mathrm{cm}^{2}\right)$ at $v=3 \mathrm{~mm} / \mathrm{s}$. Averaged line width is depicted in $\mathrm{nm}$; (b) RB manufactured with the same $P$ but at $v=2 \mathrm{~mm} / \mathrm{s}$. Common defects are showed: merged lines, formed bubbles and residual material called "skirt"; (c) The thinnest observed feature of $103 \mathrm{~nm}$; (d) Bulky arc-type objects. Distance between columns is marked with arrowed line and presented in numbers; $(\mathbf{a}, \mathbf{c})$ are top view of the structures, $(\mathbf{b}, \mathbf{d})$ were obtained at 45 degrees angle.

Finally, the fine RB structures were tested for thermal post-processing and proved its potential for the downscaling by up to $50 \%$ via pyrolysis, which is a known technique for hybrid materials [67-69], yet have not been applied to plant-based bioresins [70]. In Figure $7 b, c$, the line thickness was decreased, possibly due to several reasons: due to the polymer thermal decomposition which started at such high temperatures and due to the necking of the line due to its plastic deformation caused by the tensile stress that occurred as the distance between the line supports increasing. The line does not break due to the elongation of the flexible chains present in the polymer. The formed stable neck describes polymer $75 \mathrm{C} / 25 \mathrm{D}$ as a ductile polymer suitable for thermal post-processing via pyrolysis which is a powerful method for further downscaling the micro-/nano-objects and densifying the material for optimizing the functional performance of the 3D structures. 


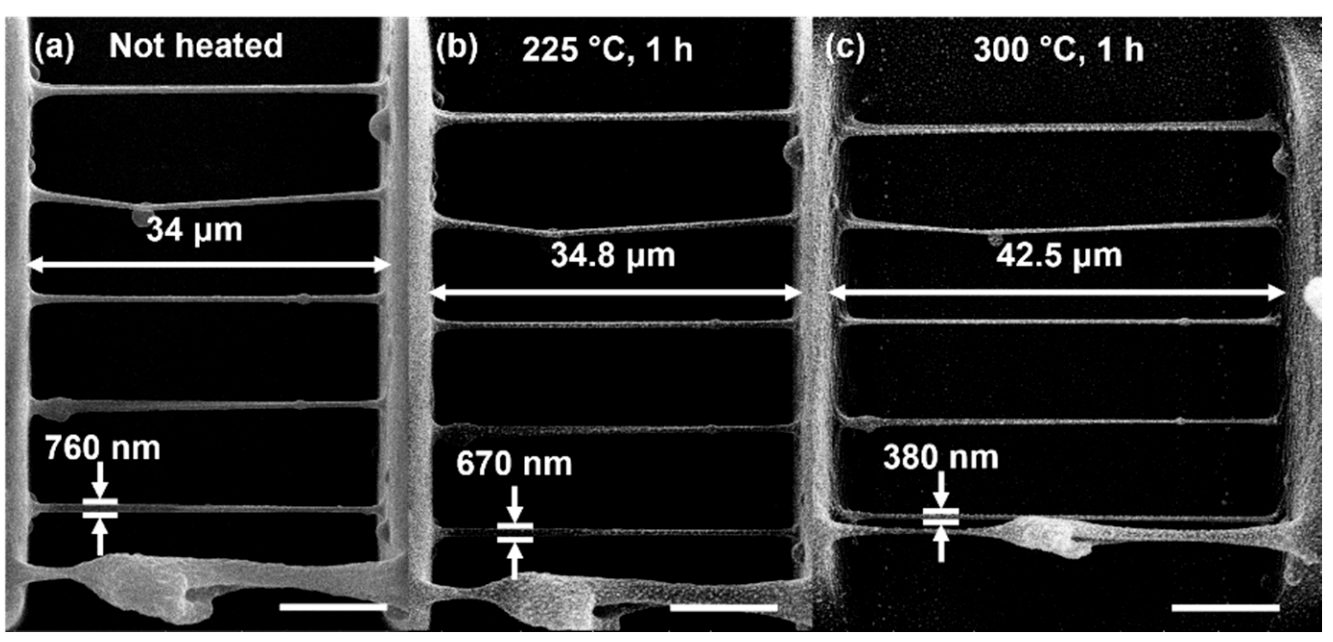

Figure 7. The SEM images of the same RB structure and applied thermal treatment in ambient surrounding: (a) before, (b) after $1 \mathrm{~h}$ at $225^{\circ} \mathrm{C}$, (c) after additional $1 \mathrm{~h}$ at $300{ }^{\circ} \mathrm{C}$. It is seen that the structures preserve their shape while downscaling $12 \%$ and $50 \%$ of their initial dimensions (the line thickness). Scale bar in all images represents $10 \mu \mathrm{m}$.

\section{Conclusions}

Vegetable-oil-based thiol-ene/thiol-epoxy polymers were synthesized from acrylated epoxidized soybean oil, epoxidized linseed oil and thiols (benzene-1,3-dithiol and pentaerythritol tetra(3-mercaptopropionate)) using ethyl(2,4,6-thimethylbenzoyl) phenyl phosphinate as the photoinitiator and 1-methylimidazole as the catalyst. Benzene-1,3-dithiol was the most reactive thiol with the lowest activation temperature due to the higher nucleophilicity of thiophenolate anion compared to the thiolate from pentaerythritol tetra(3mercaptopropionate). The use of benzene-1,3-dithiol for thiol/epoxy reaction led to the cross-linked polymers with the higher glass transition temperature, stress at break, and Young's modulus due to the more rigid structure. Dynamic-mechanical thermal analysis, thermogravimetry, and mechanical testing of thiol-epoxy polymers confirmed that epoxidized linseed oil can be a good biobased alternative to bisphenol A diglycidyl ether in thiol-epoxy thermal curing reactions. Rheometry and mechanical testing showed that dual cured polymers exhibited higher rigidity and higher tensile strength, and Young's modulus values compared with UV-cured thiol-ene polymers. Femtosecond LDW lithography was employed for validating the applicability of biobased thiol-ene/thiol-epoxy resin with pentaerythritol tetra(3-mercaptopropionate) for high resolution O3DP. Namely, the possibility was demonstrated to perform arc-type microstructures in a reproducible manner and $100 \mathrm{~nm}$ individual features were obtained by optimizing the exposure and developing conditions. Additionally, the structures were heated up to $300{ }^{\circ} \mathrm{C}$ and isotropic shrinkage was achieved. The results show a high potential of the vegetable-oil-based resins for high fidelity rapid prototyping and additive manufacturing.

Author Contributions: Conceptualization, S.G., A.S. and J.O.; methodology, S.G., E.S., M.M. and J.O.; investigation, S.G., A.N., E.S.; writing—original draft preparation, S.G. and E.S.; writing—review and editing, M.M., A.S., J.O; visualization, S.G. and E.S; supervision, M.M., A.S. and J.O. All authors have read and agreed to the published version of the manuscript.

Institutional Review Board Statement: Not applicable.

Informed Consent Statement: Not applicable.

Data Availability Statement: The data presented in this study are available on request from the corresponding author. 
Acknowledgments: This research was funded by the Research Council of Lithuania (project No. S-MIP-20-17). A. Serra would like to thank MCIU (Ministerio de Ciencia, Innovación y Universidades) and FEDER (Fondo Europeo de Desarrollo Regional) (MAT2017-82849-C2-1-R).

Conflicts of Interest: The authors declare no conflict of interest.

\section{References}

1. Barner-Kowollik, C.; Bastmeyer, M.; Blasco, E.; Delaittre, G.; Müller, P.; Richter, B.; Wegener, M. 3D Laser Micro- and Nanoprinting: Challenges for Chemistry. Angew. Chem. Int. Ed. 2017, 56, 15828-15845. [CrossRef]

2. Skliutas, E.; Lebedevaite, M.; Kabouraki, E.; Baldacchini, T.; Ostrauskaite, J.; Vamvakaki, M.; Farsari, M.; Juodkazis, S.; Malinauskas, M. Polymerization mechanisms initiated by spatio-temporally confined light. Nanophotonics 2021, 10, 1211-1242. [CrossRef]

3. Li, F.; Macdonald, N.P.; Guijt, R.M.; Breadmore, M.C. Increasing the functionalities of 3D printed microchemical devices by single material, multimaterial, and print-pause-print 3D printing. Lab Chip 2018, 19, 35-49. [CrossRef] [PubMed]

4. Wu, Z.-L.; Qi, Y.-N.; Yin, X.-J.; Yang, X.; Chen, C.-M.; Yu, J.-Y.; Yu, J.-C.; Lin, Y.-M.; Hui, F.; Liu, P.-L.; et al. Polymer-Based Device Fabrication and Applications Using Direct Laser Writing Technology. Polymers 2019, 11, 553. [CrossRef] [PubMed]

5. Telitel, S.; Morris, J.C.; Guillaneuf, Y.; Clément, J.-L.; Morlet-Savary, F.; Spangenberg, A.; Malval, J.-P.; Lalevée, J.; Gigmes, D.; Soppera, O. Laser Direct Writing of Arbitrary Complex Polymer Microstructures by Nitroxide-Mediated Photopolymerization. ACS Appl. Mater. Interfaces 2020, 12, 30779-30786. [CrossRef]

6. Konuray, O.; Fernández-Francos, X.; Ramis, X.; Serra, À. State of the Art in Dual-Curing Acrylate Systems. Polymers 2018, 10, 178. [CrossRef]

7. Ramis, X.; Fernandez-Francos, X.; de La Flor, S.; Ferrando, F.; Serra, A. Click-Based Dual-Curing Thermosets and Their Applications. In Thermosets: Structure, Properties, and Applications, 2nd ed.; Guo, Q., Ed.; Elsevier: Amsterdam, The Netherlands, 2018; pp. 511-541. [CrossRef]

8. Bauer, J.; Izard, A.G.; Zhang, Y.; Baldacchini, T.; Valdevit, L. Thermal post-curing as an efficient strategy to eliminate process parameter sensitivity in the mechanical properties of two-photon polymerized materials. Opt. Express 2020, 28, 20362-20371. [CrossRef]

9. Kuang, X.; Zhao, Z.; Chen, K.; Fang, D.; Kang, G.; Qi, H.J. High-Speed 3D Printing of High-Performance Thermosetting Polymers via Two-Stage Curing. Macromol. Rapid Commun. 2018, 39, e1700809. [CrossRef] [PubMed]

10. Konuray, O.; Di Donato, F.; Sangermano, M.; Bonada, J.; Tercjak, A.; Fernandez-Francos, X.; Serra, A.; Ramis, X. Dual-curable stereolithography resins for superior thermomechanical properties. Express Polym. Lett. 2020, 14, 881-894. [CrossRef]

11. Chen, Z.; Yang, M.; Ji, M.; Kuang, X.; Qi, H.J.; Wang, T. Recyclable thermosetting polymers for digital light processing 3D printing. Mater. Des. 2021, 197, 109189. [CrossRef]

12. Fernández-Francos, X.; Konuray, O.; Ramis, X.; Serra, À.; de La Flor, S. Enhancement of 3D-Printable Materials by Dual-Curing Procedures. Materials 2020, 14, 107. [CrossRef]

13. Konuray, O.; Fernández-Francos, X.; de La Flor, S.; Ramis, X.; Serra, À. The Use of Click-Type Reactions in the Preparation of Thermosets. Polymers 2020, 12, 1084. [CrossRef]

14. Khire, V.S.; Lee, T.Y.; Bowman, C.N. Synthesis, Characterization and Cleavage of Surface-Bound Linear Polymers Formed Using Thiol-Ene Photopolymerizations. Macromolecules 2008, 41, 7440-7447. [CrossRef]

15. Hoyle, C.E.; Bowman, C.N. Thiol-Ene Click Chemistry. Angew. Chem. Int. Ed. 2010, 49, 1540-1573. [CrossRef]

16. Carioscia, J.A.; Schneidewind, L.; O’Brien, C.; Ely, R.; Feeser, C.; Cramer, N.; Bowman, C.N. Thiol-Norbornene materials: Approaches to develop high $\mathrm{T}_{\mathrm{g}}$ Thiol-Ene polymers. J. Polym. Sci. Part A Polym. Chem. 2007, 45, 5686-5696. [CrossRef]

17. Liao, C.; Kannan, K. Concentrations and Profiles of Bisphenol A and Other Bisphenol Analogues in Foodstuffs from the United States and Their Implications for Human Exposure. J. Agric. Food Chem. 2013, 61, 4655-4662. [CrossRef] [PubMed]

18. Michałowicz, J. Bisphenol A-Sources, toxicity and biotransformation. Environ. Toxicol. Pharmacol. 2014, 37, 738-758. [CrossRef]

19. Rochester, J.R.; Bolden, A.L.; Kwiatkowski, C.F. Prenatal exposure to bisphenol A and hyperactivity in children: A systematic review and meta-analysis. Environ. Int. 2018, 114, 343-356. [CrossRef]

20. Onundi, Y.; Drake, B.A.; Malecky, R.T.; DeNardo, M.A.; Mills, M.R.; Kundu, S.; Ryabov, A.D.; Beach, E.S.; Horwitz, C.P.; Simonich, M.T.; et al. A multidisciplinary investigation of the technical and environmental performances of TAML/peroxide elimination of Bisphenol A compounds from water. Green Chem. 2017, 19, 4234-4262. [CrossRef]

21. Cakmakci, E.; Şen, F.; Kahraman, M.V. Isosorbide Diallyl Based Antibacterial Thiol—Ene Photocured Coatings Containing Polymerizable Fluorous Quaternary Phosphonium Salt. ACS Sustain. Chem. Eng. 2019, 7, 10605-10615. [CrossRef]

22. Tian, Y.; Wang, Q.; Cheng, J.; Zhang, J. A fully biomass based monomer from itaconic acid and eugenol to build degradable thermosets via Thiol—Ene click chemistry. Green Chem. 2020, 22, 921-932. [CrossRef]

23. Dai, J.; Ma, S.; Zhu, L.; Wang, S.; Yang, L.; Song, Z.; Liu, X.; Zhu, J. UV-thermal dual cured anti-bacterial Thiol—Ene networks with superior performance from renewable resources. Polymer 2017, 108, 215-222. [CrossRef]

24. Jawerth, M.; Johansson, M.; Lundmark, S.; Gioia, C.; Lawoko, M. Renewable Thiol-Ene Thermosets Based on Refined and Selectively Allylated Industrial Lignin. ACS Sustain. Chem. Eng. 2017, 5, 10918-10925. [CrossRef]

25. Navaruckiene, A.; Kasetaite, S.; Ostrauskaite, J. Vanillin-based thiol-ene systems as photoresins for optical 3D printing. Rapid Prototyp. J. 2019, 26, 402-408. [CrossRef] 
26. Navaruckiene, A.; Bridziuviene, D.; Raudoniene, V.; Rainosalo, E.; Ostrauskaite, J. Influence of Vanillin Acrylate-Based Resin Composition on Resin Photocuring Kinetics and Antimicrobial Properties of the Resulting Polymers. Materials 2021, 14, 653. [CrossRef]

27. Wang, C.; Ding, L.; He, M.; Wei, J.; Li, J.; Lu, R.; Xie, H.; Cheng, R. Facile one-step synthesis of bio-based AESO resins. Eur. J. Lipid Sci. Technol. 2016, 118, 1463-1469. [CrossRef]

28. Kasetaite, S.; de La Flor, S.; Serra, À..; Ostrauskaitè, J. Effect of Selected Thiols on Cross-Linking of Acrylated Epoxidized Soybean Oil and Properties of Resulting Polymers. Polymers 2018, 10, 439. [CrossRef] [PubMed]

29. Miezinyte, G.; Ostrauskaite, J.; Rainosalo, E.; Skliutas, E.; Malinauskas, M. Photoresins based on acrylated epoxidized soybean oil and benzenedithiols for optical 3D printing. Rapid Prototyp. J. 2019, 25, 378-387. [CrossRef]

30. Hoyle, C.E.; Lowe, A.B.; Bowman, C.N. Thiol-click chemistry: A multifaceted toolbox for small molecule and polymer synthesis. Chem. Soc. Rev. 2010, 39, 1355-1387. [CrossRef]

31. Cengiz, N.; Rao, J.; Sanyal, A.; Khan, A. Designing functionalizable hydrogels through Thiol—Epoxy coupling chemistry. Chem. Commun. 2013, 49, 11191-11193. [CrossRef] [PubMed]

32. Belmonte, A.; Guzmán, D.; Fernández-Francos, X.; de La Flor, S. Effect of the Network Structure and Programming Temperature on the Shape-Memory Response of Thiol-Epoxy "Click" Systems. Polymers 2015, 7, 2146-2164. [CrossRef]

33. De, S.; Khan, A. Efficient synthesis of multifunctional polymers via Thiol-Epoxy "click" chemistry. Chem. Commun. 2012, 48, 3130-3132. [CrossRef] [PubMed]

34. Konuray, A.O.; Fernández-Francos, X.; Ramis, X. Latent curing of epoxy-thiol thermosets. Polymer 2017, 116, 191-203. [CrossRef]

35. Fernández-Francos, X.; Konuray, A.-O.; Belmonte, A.; de La Flor, S.; Serra, À.; Ramis, X. Sequential curing of off-stoichiometric Thiol-Epoxy thermosets with a custom-tailored structure. Polym. Chem. 2016, 7, 2280-2290. [CrossRef]

36. Endo, T.; Sanda, F. Design of latent catalysts and their application to polymer synthesis. Macromol. Symp. 1996, 107, 237-242. [CrossRef]

37. Miao, S.; Wang, P.; Su, Z.; Zhang, S. Vegetable-oil-based polymers as future polymeric biomaterials. Acta Biomater. 2014, 10, 1692-1704. [CrossRef]

38. Nouailhas, H.; Aouf, C.; Le Guerneve, C.; Caillol, S.; Boutevin, B.; Fulcrand, H. Synthesis and properties of biobased epoxy resins Part 1. Glycidylation of flavonoids by epichlorohydrin. J. Polym. Sci. Part A Polym. Chem. 2011, 49, 2261-2270. [CrossRef]

39. Aouf, C.; Benyahya, S.; Esnouf, A.; Caillol, S.; Boutevin, B.; Fulcrand, H. Tara tannins as phenolic precursors of thermosetting epoxy resins. Eur. Polym. J. 2014, 55, 186-198. [CrossRef]

40. Benyahya, S.; Aouf, C.; Caillol, S.; Boutevin, B.; Pascault, J.P.; Fulcrand, H. Functionalized green tea tannins as phenolic prepolymers for bio-based epoxy resins. Ind. Crop. Prod. 2014, 53, 296-307. [CrossRef]

41. A Baroncini, E.; Yadav, S.K.; Palmese, G.R.; Stanzione, J.F. Recent advances in bio-based epoxy resins and bio-based epoxy curing agents. J. Appl. Polym. Sci. 2016, 133, 44103. [CrossRef]

42. Shibata, M.; Ohkita, T. Fully biobased epoxy resin systems composed of a vanillin-derived epoxy resin and renewable phenolic hardeners. Eur. Polym. J. 2017, 92, 165-173. [CrossRef]

43. Jiang, H.; Sun, L.; Zhang, Y.; Liu, Q.; Ru, C.; Zhang, W.; Zhao, C. Novel biobased epoxy resin thermosets derived from eugenol and vanillin. Polym. Degrad. Stab. 2019, 160, 45-52. [CrossRef]

44. Guzmán, D.; Ramis, X.; Fernández-Francos, X.; de La Flor, S.; Serra, A. New bio-based materials obtained by thiol-ene/thiol-epoxy dual curing click procedures from eugenol derivates. Eur. Polym. J. 2017, 93, 530-544. [CrossRef]

45. Guzmán, D.; Ramis, X.; Fernández-Francos, X.; de La Flor, S.; Serra, A. Preparation of new biobased coatings from a triglycidyl eugenol derivative through thiol-epoxy click reaction. Prog. Org. Coat. 2018, 114, 259-267. [CrossRef]

46. Guzmán, D.; Serra, A.; Ramis, X.; Fernández-Francos, X.; de La Flor, S. Fully renewable thermosets based on bis-eugenol prepared by thiol-click chemistry. React. Funct. Polym. 2019, 136, 153-166. [CrossRef]

47. Guzmán, D.; Santiago, D.; Serra, À.; Ferrando, F. Novel Bio-Based Epoxy Thermosets Based on Triglycidyl Phloroglucinol Prepared by Thiol-Epoxy Reaction. Polymers 2020, 12, 337. [CrossRef] [PubMed]

48. Fourcade, D.; Ritter, B.S.; Walter, P.; Schönfeld, R.; Mülhaupt, R. Renewable resource-based epoxy resins derived from multifunctional poly(4-hydroxybenzoates). Green Chem. 2013, 15, 910-918. [CrossRef]

49. Güner, F.S.; Yağc1, Y.; Erciyes, A.T. Polymers from triglyceride oils. Prog. Polym. Sci. 2006, 31, 633-670. [CrossRef]

50. Xia, Y.; LaRock, R.C. Vegetable oil-based polymeric materials: Synthesis, properties, and applications. Green Chem. 2010, 12, 1893-1909. [CrossRef]

51. Zhang, C.; Garrison, T.F.; Madbouly, S.A.; Kessler, M.R. Recent advances in vegetable oil-based polymers and their composites. Prog. Polym. Sci. 2017, 71, 91-143. [CrossRef]

52. Llevot, A. Sustainable Synthetic Approaches for the Preparation of Plant Oil-Based Thermosets. J. Am. Oil Chem. Soc. 2016, 94, 169-186. [CrossRef]

53. Ng, F.; Couture, G.; Philippe, C.; Boutevin, B.; Caillol, S. Bio-Based Aromatic Epoxy Monomers for Thermoset Materials. Molecules 2017, 22, 149. [CrossRef] [PubMed]

54. Sahoo, S.K.; Mohanty, S.; Nayak, S.K. Synthesis and characterization of bio-based epoxy blends from renewable resource based epoxidized soybean oil as reactive diluent. Chin. J. Polym. Sci. 2014, 33, 137-152. [CrossRef]

55. Kumar, S.; Krishnan, S.; Mohanty, S.; Nayak, S.K. Synthesis and characterization of petroleum and biobased epoxy resins: A review. Polym. Int. 2018, 67, 815-839. [CrossRef] 
56. John, G.; Nagarajan, S.; Vemula, P.K.; Silverman, J.R.; Pillai, C. Natural monomers: A mine for functional and sustainable materials-Occurrence, chemical modification and polymerization. Prog. Polym. Sci. 2019, 92, 158-209. [CrossRef]

57. Yim, Y.-J.; Rhee, K.Y.; Park, S.-J. Fracture toughness and ductile characteristics of diglycidyl ether of bisphenol-A resins modified with biodegradable epoxidized linseed oil. Compos. Part B Eng. 2017, 131, 144-152. [CrossRef]

58. Feng, Y.; Hu, Y.; Man, L.; Yuan, T.; Zhang, C.; Yang, Z. Biobased thiol-epoxy shape memory networks from gallic acid and vegetable oils. Eur. Polym. J. 2019, 112, 619-628. [CrossRef]

59. Lebedevaite, M.; Ostrauskaite, J. Influence of photoinitiator and temperature on photocross-linking kinetics of acrylated epoxidized soybean oil and properties of the resulting polymers. Ind. Crop. Prod. 2021, 161, 113210. [CrossRef]

60. Krongauz, V.V. Diffusion in polymers dependence on crosslink density. J. Therm. Anal. Calorim. 2010, 102, 435-445. [CrossRef]

61. DeVoe, R.J.; Kalweit, H.W.; Leatherdale, C.A.; Williams, T.R. Voxel Shapes in Two-Photon Microfabrication. In Multiphoton Absorption and Nonlinear Transmission Processes: Materials, Theory, and Applications, Proceedings of the International Symposium on Optical Science and Technology, Seattle, WA, USA, 14 February 2003; SPIE: Bellingham, WA, USA, 2003. [CrossRef]

62. Lebedevaite, M.; Ostrauskaite, J.; Skliutas, E.; Malinauskas, M. Photoinitiator Free Resins Composed of Plant-Derived Monomers for the Optical $\mu$-3D Printing of Thermosets. Polymers 2019, 11, 116. [CrossRef]

63. Guzmán, D.; Ramis, X.; Fernández-Francos, X.; Serra, A. Enhancement in the Glass Transition Temperature in Latent Thiol-Epoxy Click Cured Thermosets. Polymers 2015, 7, 680-694. [CrossRef]

64. Guzmán, D.; Ramis, X.; Fernández-Francos, X.; Serra, A. Preparation of click thiol-ene/thiol-epoxy thermosets by controlled photo/thermal dual curing sequence. RSC Adv. 2015, 5, 101623-101633. [CrossRef]

65. Rothammer, M.; Heep, M.-C.; Von Freymann, G.; Zollfrank, C. Enabling direct laser writing of cellulose-based submicron architectures. Cellulose 2018, 25, 6031-6039. [CrossRef]

66. Skliutas, E.; Lebedevaite, M.; Kasetaite, S.; Rekštyte, S.; Lileikis, S.; Ostrauskaite, J.; Malinauskas, M. A Bio-Based Resin for a Multi-Scale Optical 3D Printing. Sci. Rep. 2020, 10, 9758. [CrossRef] [PubMed]

67. Li, J.; Jia, B.; Gu, M. Engineering stop gaps of inorganic-organic polymeric 3D woodpile photonic crystals with post-thermal treatment. Opt. Express 2008, 16, 20073-20080. [CrossRef]

68. Seniutinas, G.; Weber, A.; Padeste, C.; Sakellari, I.; Farsari, M.; David, C. Beyond $100 \mathrm{~nm}$ resolution in 3D laser lithography-Post processing solutions. Microelectron. Eng. 2018, 191, 25-31. [CrossRef]

69. Gailevičius, D.; Padolskytè, V.; Mikoliūnaitè, L.; Šakirzanovas, S.; Juodkazis, S.; Malinauskas, M. Additive-manufacturing of 3D glass-ceramics down to nanoscale resolution. Nanoscale Horiz. 2018, 4, 647-651. [CrossRef]

70. Sharipova, M.I.; Baluyan, T.G.; Abrashitova, K.A.; Kulagin, G.E.; Petrov, A.K.; Chizhov, A.S.; Shatalova, T.B.; Chubich, D.; Kolymagin, D.A.; Vitukhnovsky, A.G.; et al. Effect of pyrolysis on microstructures made of various photoresists by two-photon polymerization: Comparative study. Opt. Mater. Express 2021, 11, 371-384. [CrossRef] 